\title{
Changes in Microstructure and Rheological Properties of Squid Mantle during Storage
}

\author{
Mutsuko KugInO, ${ }^{1} \mathrm{Kenji} \mathrm{KugINO}^{2}$ and Tadashi OGAwA ${ }^{3}$ \\ ${ }^{1}$ Department of Home Economics, Kwassui Women's Junior College, Nagasaki 850, Japan \\ ${ }^{2}$ Department of Nutrition, Faculty of Home Economics, Yamaguchi Prefectural University, Yamaguchi 753, Japan \\ ${ }^{3}$ Department of Nutrition, the School of Medicine, Tokushima University, Tokushima 770, Japan
}

Received September 17, 1996

\begin{abstract}
Histological and physicochemical changes in the mantle muscle tissue of squid (Sepioteuthis lessoniana) during storage were studied. When raw squid mantles were broken parallel to the circular musculature, the rupture energy (RE) was significantly lowered along with the storage. In the case of breaking across the circular musculature, the RE was slightly lowered but the yield point (YP) in the stress-strain curve shifted to a larger strain during storage. In the case of heated squid meat, the YP shifted to a lower strain during storage. The electron microscopic observation of the muscle tissue of raw squid indicated that a number of voids appeared between the muscle bundles and the muscle fibers during storage, and after cooking, obvious detachment was observed between the muscle fibers and muscle bundles. No significant changes in the molecular sizes of major protein components (muscle fibril proteins) were observed, indicating that the muscle fibril proteins were not degraded.
\end{abstract}

Keywords: squid mantle, microstructure, rheology, storage time

Compared with general fishes, the preference for squid meat largely depends not on the taste but on the physicochemical properties such as texture (Otwell \& Hamann, 1979; Nakamura et al., 1985; Kugino, M. \& Kugino, K., 1994). It is therefore important to understand how the physicochemical properties of squid meat are changed during processing. It is important particularly in cooking which largely affects the physicochemical properties of squid meat. However, few experimental reports have been published relating to physicochemical changes in cooked squid meat, and thus no standard evaluation has been established so far. It was reported that cooked squid meat was softened and showed a decreased shear force in experiments with Illex argentinus (Kolodziejska et al., 1987), Illex illecebroses (Stanley \& Hultin, 1982) and Loligo pealei (Otwell \& Hamann, 1979). On the other hand, it is generally considered that squid meat becomes gummy on cooking (Ampola, 1974). Namely, the physicochemical changes in squid meat caused by cooking are not merely as simple as lowering the shear force. Our recent studies demonstrated that boiled Sepioteuthis lessoniana (Kugino, M. \& Kugino, K., 1994, 1995) and Sepia officinalis (Kugino, 1994) showed decreased rupture energies and that the stressstrain curves in cooking treatment largely differ from those of raw squids.

It is known that the freshness of squid meat rapidly decreases (Nakamura et al., 1985). Thus it can be easily assumed that the freshness of a sample largely affects the rheological properties for evaluating squid meat. This is seemingly one of the reasons for the difficulties in the establishment of a standard evaluation of the physicochemical changes of squid mantle caused by cooking. In this study, fresh squid immediately after slaughter and cooked specimens were used as the samples, and the histological, physico- chemical and protein structural changes in squid mantle along with storage were examined.

\section{Materials and Methods}

Squid sample The sample squid was Japanese oval squid (aori-ika, Sepioteuthis lessoniana). The squids, caught off the coast of Nagasaki, Japan, in February were obtained, and the mantles were used in all of the experiments. The living squids used in the experiment weighed approximately $1000 \mathrm{~g}$ and measured approximately $10 \mathrm{~mm}$ in thickness at the middle of the mantle. The living squid was decapitated and immediately cut open; the mantle on the abdominal side was incised along the body axis; then the viscera, head, arms and skin (1st and 2nd tunic of the outer layer) were removed and the mantle was used as the samples.

Storage and sampling Immediately after slaughter, the mantles were stored in the refrigerator at $5^{\circ} \mathrm{C}$ and sampled after $0,3,6,9,12$ and $24 \mathrm{~h}$ of storage. The mantles stored for each period were cooked for $6 \mathrm{~min}$ in boiling water. After cooking, the mantles were cooled to room temperature by rinsing with running tap water. These raw and cooked squid mantles were used for the following measurements.

Measurement of contractile percentage of mantle The contraction of mantle muscle was measured according to Mishima et al. (1995) with a few modifications. Briefly, 15 -mm-wide test pieces $(80 \mathrm{~mm}$ in length) were cut from the uniform thickness portion in the middle of the mantle perpendicular to the body axis, fixed at one end by a pin and kept hanging in a closed vessel containing saturated steam. The mantle in the vessel was then stored in a refrigerator at $5^{\circ} \mathrm{C}$, and the length of the mantle was measured at specific time intervals $(0,1,3,5,7,9,12,15$ and $24 \mathrm{~h})$. The ratio of contractile length for each mantle was expressed as the 
percentage (\%) of the length at each time against that at $0 \mathrm{~h}$.

Measurement of rheological properties The rheological properties of the squid mantle were measured according to the method previously proposed (Kugino et al., 1993; Kugino, M. \& Kugino, K., 1994). Parts of the raw and cooked mantles stored in a refrigerator were cut out for measuring the rupture properties. The 15-mm-wide test pieces were cut from the uniform thickness portion in the middle of the mantle which was parallel and perpendicular to the body axis. The rheological properties were measured using an RE-3305 rheometer (Yamaden Co., Tokyo) using a $20 \mathrm{~kg}$ load cell. The specimen was placed on the stage of the rheometer with the outer tunic up, and the rupture stress, rupture strain and rupture energy were measured using the constant speed compressive rupture test (compression rate, $1 \mathrm{~mm} / \mathrm{s}$; clearance, $0.05 \mathrm{~mm}$; temperature, $25^{\circ} \mathrm{C}$ ) with a 0.3 -mm-thick stainless steel plate plunger.

Sodium dodecyl sulfate polyacrylamide gel-electrophoresis (SDS-PAGE) The samples were homogenized with a solution containing $4 \%(\mathrm{w} / \mathrm{v})$ SDS, $10 \%(\mathrm{v} / \mathrm{v}) \beta$-mercaptoethanol, 20\% (v/v) glycerol and $125 \mathrm{~mm}$ Tris- $\mathrm{HCl}(\mathrm{pH} 6.8)$ and heated in a boiling water bath for $5 \mathrm{~min}$. Proteins were separated by means of SDS-PAGE on $12 \%$ polyacrylamide gels according to Laemmli (1970). The proteins separated on the gels were stained with Coomassie Brilliant Blue R-250.

Electron microscopy The electron microscopic observations of the musculature of the raw and the cooked squid mantle were completed according to the previously proposed method (Kugino \& Kishino, 1991) using an HU-12 electron microscope (Hitachi Co., Tokyo) at $75 \mathrm{kV}$.

\section{Results}

Figure 1 shows contraction of raw squid mantle after slaughter. The contraction of the mantle muscle tissue started immediately after slaughter. The contractile percentage reached a peak after storage for $9 \mathrm{~h}$ and maintained an almost constant level for $24 \mathrm{~h}$ thereafter. Figure 2 shows SDS-PAGE patterns of the proteins of samples obtained from the raw and

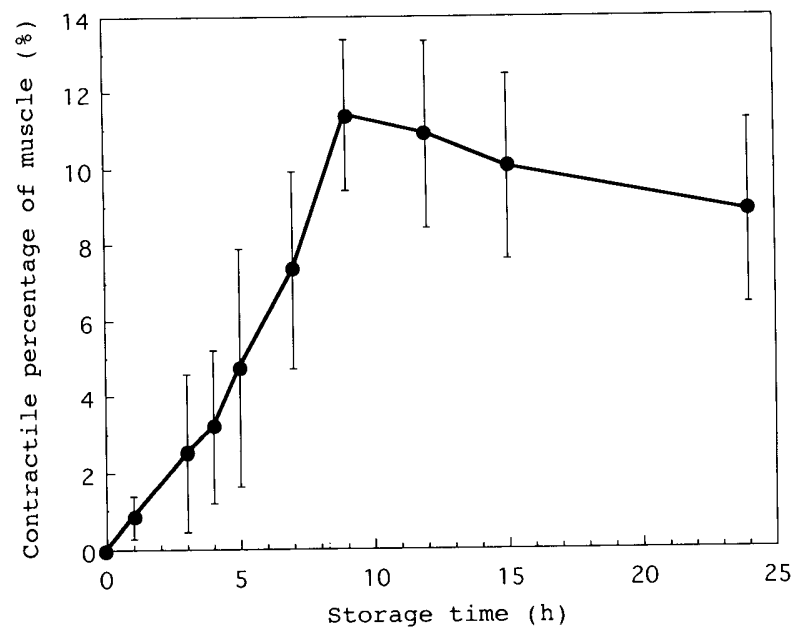

Fig. 1. Changes in contractile percentage of squid mantle muscle during storage at $5^{\circ} \mathrm{C}$. Values represent means and standard deviations for 6 separate experiments. cooked mantle of each specimen. No significant difference was observed between the electrophoretic patterns of the raw mantle and the cooked one at any storage time. However, the electrophoretic patterns of the mantle proteins of long storage samples showed some minor changes. In the mantle sample stored for $24 \mathrm{~h}$, the band of the molecular weight of about 54,000 (arrow-A) was reduced while the bands of the molecular weights of about 21,000 (arrow-B) and about 19,000 (arrow-C) became indefinite.

Figure 3 shows the rupture energies of the raw mantle and the cooked mantle. The rupture energy of the fresh mantle had anisotropic mechanical features. The sample broken parallel to the circular musculature showed an extremely higher rupture energy than the sample broken across the circular musculature (Fig. 3-a). Regarding the cooked mantle, the sample broken parallel to the circular musculature showed a considerably low rupture energy (Fig. 3-b), which indicated that the squid meat was softened by cooking as previously reported (Kugino, M. \& Kugino, K., 1994). When the mantle was stored, the sample broken parallel to the circular musculature showed a rapid decrease in rupture energy. The mantle sample stored for $12 \mathrm{~h}$ or longer showed nearly the same rupture energy as that of the sample broken across the circular musculature along with the storage time (Fig. 3-a). As the storage was prolonged, the rupture energies of the cooked mantle samples were gradually lowered regardless of the direction of breakage (Fig. 3-b).

Figures 4 and 5 show the stress-strain curves of these samples. When the raw mantle was broken parallel to the circular musculature (Fig. 4-a), the stress was gradually lowered as the storage was prolonged, though no change was observed in the stress-strain curve pattern. When the raw mantle was broken across the circular musculature (Fig. 4-b), the yield point gradually shifted to a larger strain as the

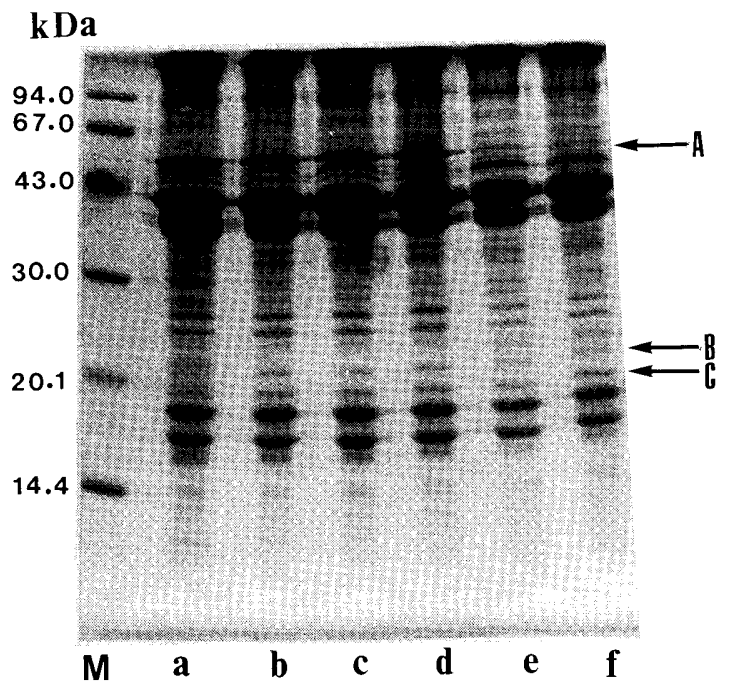

Fig. 2. SDS-PAGE pattern of whole proteins of squid mantle. Storage time and conditions of the mantle are as follows: (a) $0 \mathrm{~h}$ after killing; raw, (b) $0 \mathrm{~h}$ after killing; cooked for 5 min at $100^{\circ} \mathrm{C}$, (c) $6 \mathrm{~h}$ after killing; raw, (d) $6 \mathrm{~h}$ after killing; cooked for $5 \mathrm{~min}$ at $100^{\circ} \mathrm{C}$, (e) $24 \mathrm{~h}$ after killing; raw, (f) $24 \mathrm{~h}$ after killing; cooked for $5 \mathrm{~min}$ at $100^{\circ} \mathrm{C}$. Sample applied on each lane corresponds to $300 \mu \mathrm{g}$ of squid mantle tissue. 
storage was prolonged. In contrast, when the cooked mantle was broken across the circular musculature (Fig. 5-b), the yield point shifted to a lower strain as the storage was prolonged. Figure 6 shows electron micrographs of the mantle tissues of raw and cooked squid samples. The raw mantle tissue after storage for $24 \mathrm{~h}$ showed a number of voids (double arrow) formed between the muscle bundles and a number of small voids (arrow) formed between muscle fibers (Fig. 6-b). When fresh mantle was cooked (Fig. 6-c), in contrast, no obvious detachment was observed between the muscle bundles, and the distance between the muscle bundles was very small, though the muscle fiber structure became unclear and showed many small voids. When cooked (Fig. 6-d), the muscle fibers contracted, the distance between muscle bundles was enlarged after storage for $24 \mathrm{~h}$ (double arrow) and obvious detachment was observed between the muscle fibers (arrow).
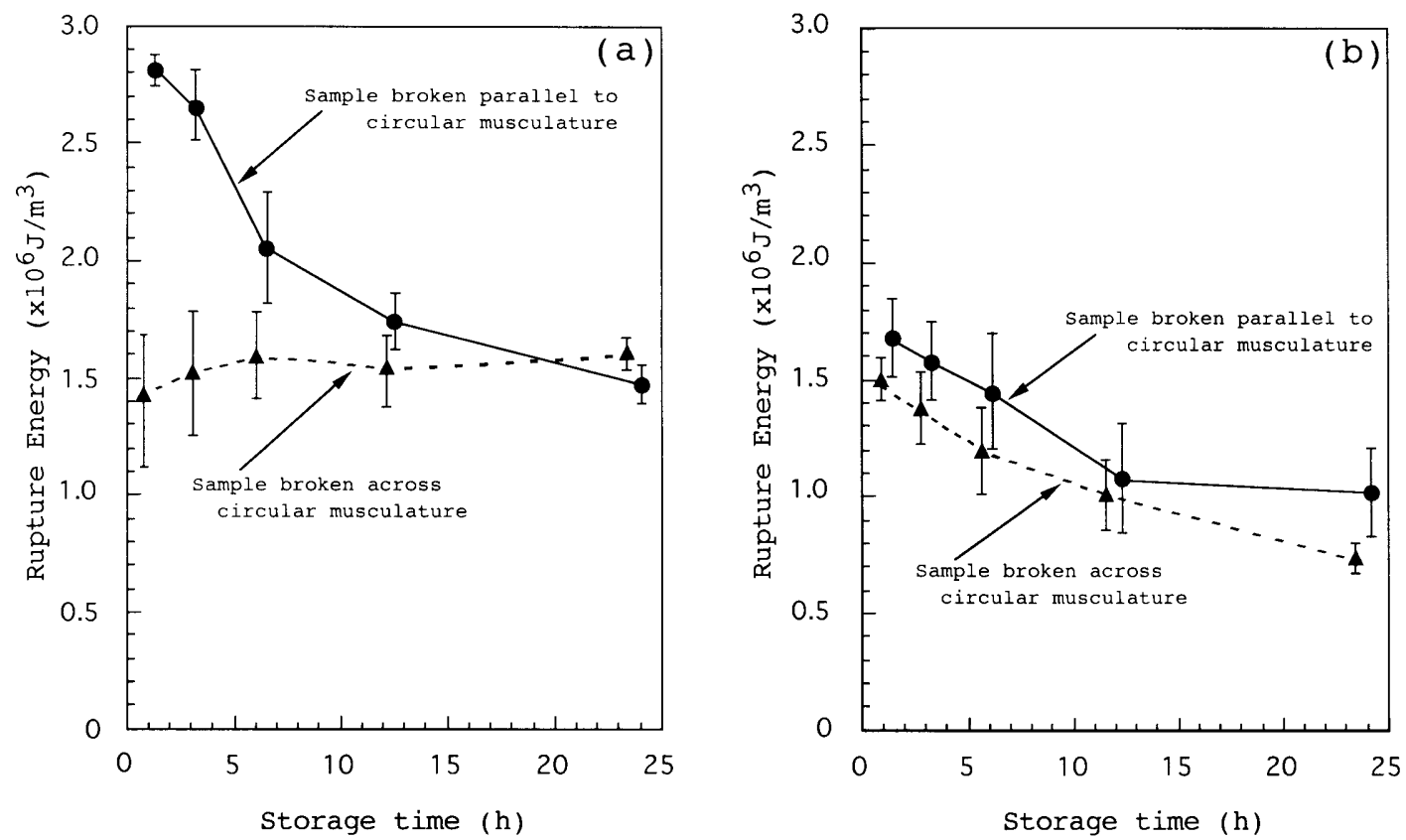

Fig. 3. Changes in rupture energy of squid mantle after storage at $5^{\circ} \mathrm{C}$. (a) Rupture energy of raw squid mantle; (b) rupture energy of squid mantle cooked for $6 \mathrm{~min}$ after storage. Values represent means and standard deviations for 6 separate experiments.
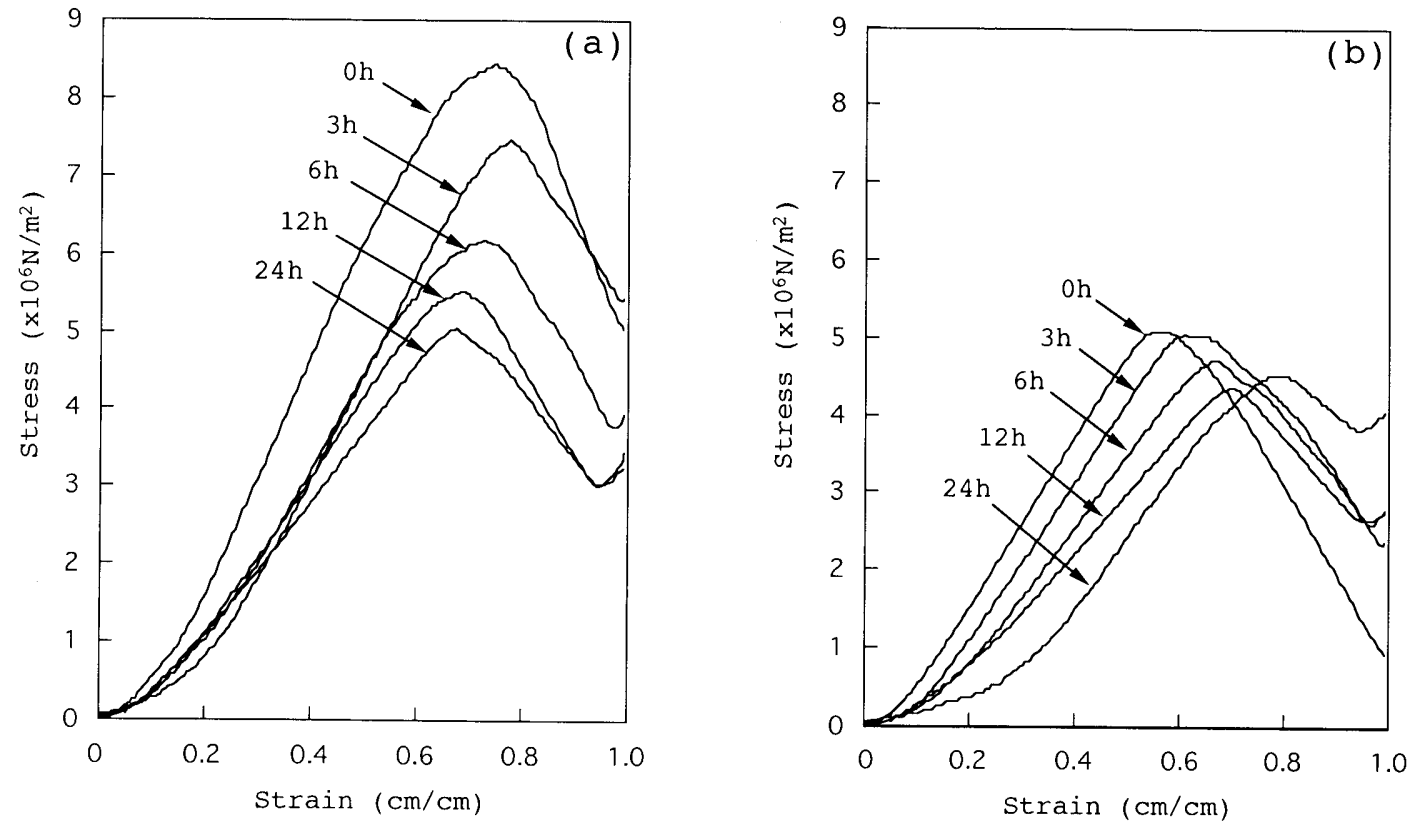

Fig. 4. Stress-strain curves of raw squid mantle after storage at $5^{\circ} \mathrm{C}$. (a) Sample broken parallel to circular musculature; (b) sample broken across circular musculature. Storage time of each curve is indicated in the figure. 

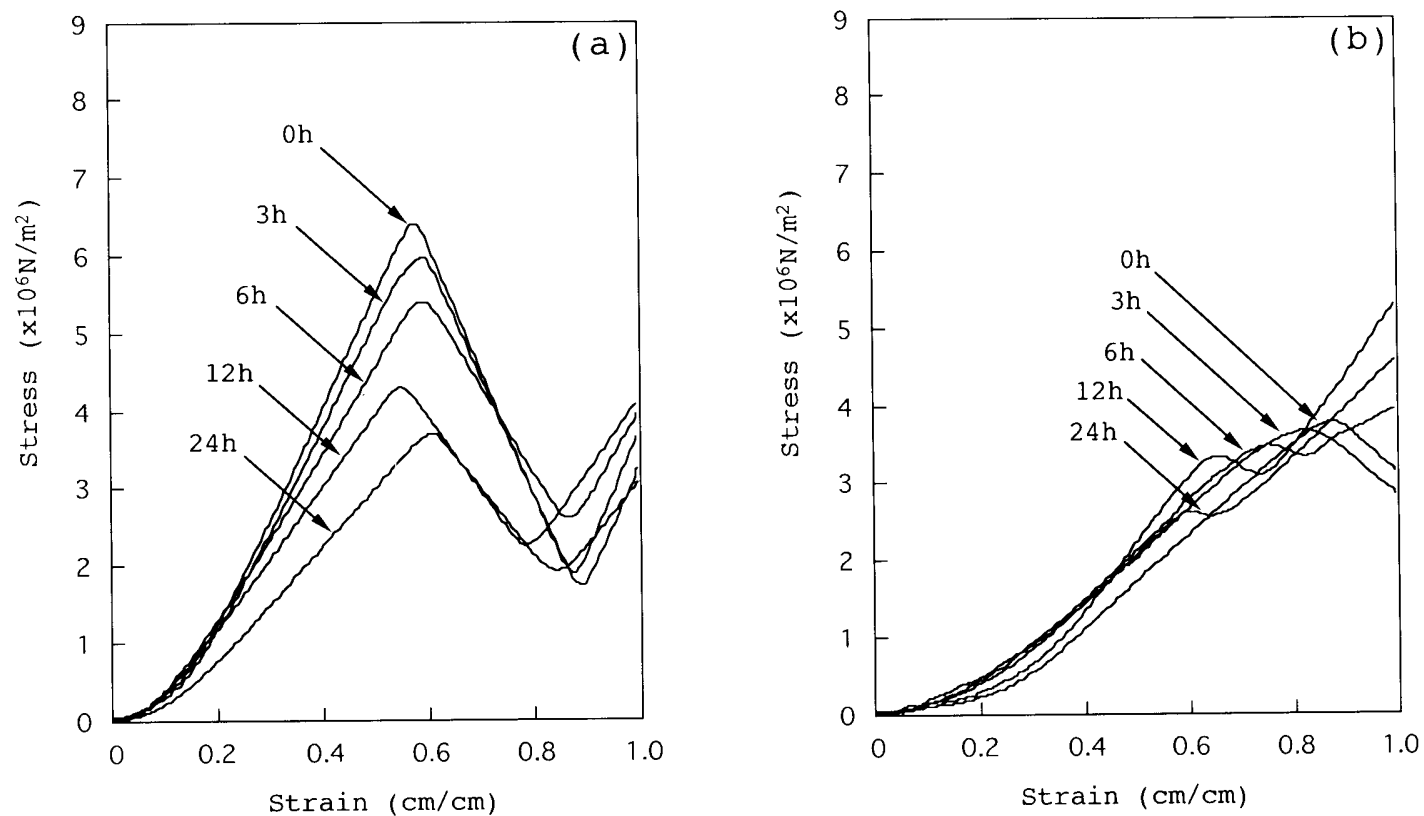

Fig. 5. Stress-strain curves of cooked squid mantle after storage at $5^{\circ} \mathrm{C}$. (a) Sample broken parallel to circular musculature; (b) sample broken across circular musculature. Storage time of each curve is indicated in the figure.
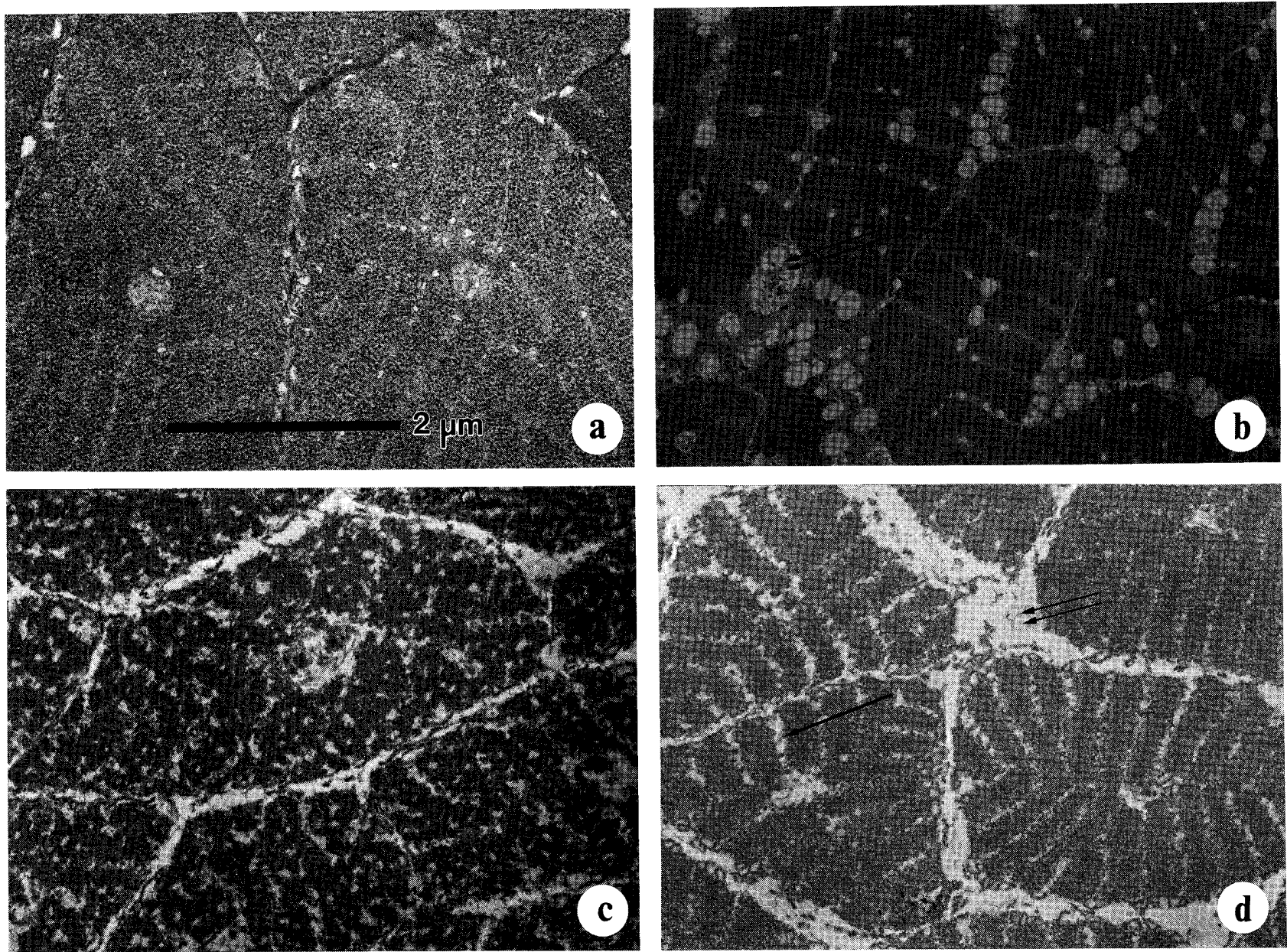

Fig. 6. Electron micrographs of raw and cooked squid mantle muscle. (a) Circular musculature of raw squid mantle immediately after slaughter; (b) circular musculature of raw squid mantle after storage at $5^{\circ} \mathrm{C}$ for $24 \mathrm{~h}$; (c) circular musculature of cooked squid mantle immediately after death; (d) circular musculature of cooked squid mantle after storage at $5^{\circ} \mathrm{C}$ for $24 \mathrm{~h}$. 


\section{Discussion}

In the results of the present experiments measuring rheological properties of the fresh squid during storage including the period of contraction after death, the rupture energy of the sample broken parallel to the circular musculature decreased during storage (Fig. 3-a). In addition, the stress-strain curve pattern of the sample broken across the circular musculature varied depending on freshness with an almost constant ratio relative to the storage time (Fig. 4-b). Changes in the rheological properties of the squid meat after death are very complicated, and the changes are affected by various factors. Therefore, it is considered that the rheological properties of squid meat would not relate particularly to the contraction after death (Fig. 1), because it was suggested that the softening of fish muscle proceeds regardless of the contraction after death (Ando et al., 1991). It is believed that physicochemical changes in fish and squid meat in association with storage are caused not by decomposition of muscle fibril proteins at the molecular level but by macro-histological changes such as the breakage of binding between muscle fibers (Kugino, M. \& Kugino, K., 1994, 1995) and the destruction of muscle fiber (Hatae et al., 1985). It was reported (Murata et al., 1995) that the softening of fish muscle tissues during cold storage is caused mainly by the disintegration of collagen fibers in the binding tissues. Also, Ando et al. (1992) performed an experiment using rainbow trout muscle (Oncorhynchus mykiss) and thus reported that the decrease in the rupture force due to storage was caused not by the weakening of the muscle fibril structure but rather by the disintegration of the binding tissues around the muscle fibers. Because squid muscle tissues have only a small amount of binding tissues which contribute to the binding between muscle fibers or unify the muscle fiber layers so as to form a strong bond (Moon \& Hulbert, 1975; Suyama, 1980), it is estimated that the disintegration of these binding tissues more seriously affects the physicochemical properties of squid mantle. The properties of most proteins constituting the squid mantle tissue are still unknown except for muscle fibril proteins (Iguchi et al., 1981; Sano et al, 1986; Kier \& Schachat, 1992; Konno \& Fukazawa, 1993). Thus it is not clear whether the three bands (minor protein components on SDS-PAGE) which disappear or become indefinite in the mantle stored for $24 \mathrm{~h}$ (Fig. 2) correspond to the molecules of collagen. However, the formation of the voids between muscle fibers and muscle bundles (Fig. 6) may be caused by the decomposition of the binding proteins constituting the binding tissues, so that the binding tissues participating in the binding of muscle fibers are rapidly disintegrated during storage. As the result, squid meat becomes very fragile in the presence of an external force applied in parallel to the muscle fibers. It is said that squid muscle fibril proteins are considerably stable (Migita, 1953), and, when cooked, the muscle fibril proteins are not degraded but are denatured or contract structurally so as to elevate the tissue density but the muscle layer structure per se maintains an intact structure (Otwell \& Giddings, 1980; Stanley \& Smith, 1984). Our observations also showed that the molecular size of the major proteins constituting muscle fibrils were not changed. On the other hand, it is considered that when squid muscle tissues are boiled, the binding tissue networks undergo serious breakage due to solubilization and gelatinization and, in turn, disappear (Otwell \& Hamann, 1979; Stanley \& Smith, 1984; Kolodziejska et al., 1987). Accordingly, it seems that the weakening of the binding tissue structure due to a decrease in freshness during storage would largely affect changes in the rheological properties of squid meat on cooking. We have already reported (Kugino, 1994; Kugino, M. \& Kugino, K., 1994, 1995) that the softening and anisotropic mechanical features of the muscle tissues of cooked squid meat are mainly induced by the breakage of the bond between muscle bundles caused by the dehydration and contraction of muscle fiber proteins due to the heat denaturation. In addition to these phenomena, the results obtained in this experiment indicate that when a mantle of decreased freshness is cooked, serious disintegration of the bond between the muscle fibers (Fig. 6) would accelerate the weakening of the muscle layer and thus promote the softening of squid meat by cooking (Fig. 3), due to the degradation (or destruction) of some binding proteins between muscle bundles.

Acknowledgments This work was supported in part by a Grant-inAid for Scientific Research from the Ministry of Education, Science and Culture, Japan.

\section{References}

Ampola, V.G. (1974). Squid-its potential and status as a U.S. food resourse. Mar. Fish. Rev., 36, 28-32.

Ando, M., Toyohara, H., Shimizu, Y. and Sakaguchi, M. (1991). Post-mortem tenderization of fish muscle proceeds independently of resolution of rigor mortis. Bull. Jpn. Soc. Sci. Fish., 57, 1165-1169.

Ando, M., Toyohara, H. and Sakaguchi, M. (1992). Post-mortem tenderization of rainbow trout muscle caused by the disintegration of collagen fibers in the pericellular connective tissue. Bull. Jpn. Soc. Sci. Fish., 58, 567-570.

Hatae, K., Tamari, S., Miyanaga, K. and Matsumoto, J.J. (1985). Species difference and changes in the physical properties of fish muscle as freshness decreases. Nippon Suisan Gakkaishi, 51, 11551161 (in Japanese).

Iguchi, S.M.M., Tsuchiya, T. and Matsumoto, J.J. (1981). Studies on the freeze denaturation of squid actomyosin. Bull. Jpn. Soc. Sci. Fish., 47, 1499-1506.

Kier, W.M. and Schachat, F.H. (1992). Biochemical comparison of fast- and slow-contracting squid muscle. J. Exp. Biol., 168, 41-56.

Kolodziejska, I., Sikorski, Z.E. and Maria Sadowska, M. (1987). Texture of cooked mantle of squid Illex argentinus as influenced by specimen characteristics and treatments. J. Food Sci., 52, 932-935.

Konno, M. and Fukazawa, C. (1993). Autolysis of squid mantle muscle protein as affected by storage conditions and inhibitors. $J$. Food Sci., 58, 1198-1202.

Kugino, M. (1994). Influence of cooking temperature on the anisotropic rupture properties of squid mantle. Kwassui Ronbunshu, 37, 21-28 (in Japanese)

Kugino, K. and Kishino, Y. (1991). Effect of voluntary exercise on pancreatic function of rats. Nutr. Res., 11, 1273-1283.

Kugino, M. and Kugino, K. (1994). Microstructural and rheological properties of cooked squid mantle. J. Food Sci., 59, 792-796.

Kugino, M. and Kugino, K. (1995). Changes in the microstructure and rheological properties of squid mantle due to cooking in an $\mathrm{NaCl}$ solution and soy sauce. J. Home Econ. Jpn., 46, 751-757.

Kugino, M., Kugino, K. and Wu, Z. (1993). Rheological properties of dried squid mantle change on softening. J. Food Sci., 58, 321-324.

Laemmli, U.K. (1970). Cleavage of structural proteins during the assembly of the head of the bacteriophage T4. Nature, 227, 681-685.

Migita, M. (1953). Characteristics of squid meat. Nippon Suisan Gakkaishi, 18, 558-568 (in Japanese). 
Mishima, T., Fujii, J., Tachibana, K. and Tsuchimoto, M. (1995). Influence of contracture on breaking strength in carp muscle. Fish. Sci., 61, 209-213.

Moon, T.W. and Hulbert, W.C. (1975). The ultrastructure of the mantle musculature of the squid Symplectoteuthis oualaniensis. Comp. Biochem. Physiol, 52B, 145-149.

Murata, M., Ando, M. and Sakaguchi, M. (1995). Freshness and palatability of fish meat. Nippon Shokuhin Kagaku Kogaku Kaishi, 42, 462-468 (in Japanese).

Nakamura, K., Ishikawa, S., Kimoto, K. and Mizuno, Y. (1985). Changes in freshness of Japanese common squid during cold storage. Bull. Tokai Reg. Fish. Res. Lab., 118, 45-49.

Otwell, W.S. and Hamann, D.D. (1979). Textural characterization of squid: scanning electron microscopy of cooked mantle. J. Food Sci,
44, 1629-1635.

Otwell, W.S. and Giddings, G.G. (1980). Scanning electron microscopy of squid, Loligo pealei: low, cooked, and frozen mantle. Mar. Fish. Rev., 42, 67-73.

Sano, T., Noguchi, S.F., Tsuchiya, T. and Matsumoto, J.J. (1986). Contribution of paramyosin to marine meat gel characteristics. $J$. Food Sci. 51, 946-950.

Stanley, D.W. and Hultin, H.O. (1982). Quality factors in cooked north Atlantic squid. Can. Inst. Food Sci. Technol. J., 15, 277-282.

Stanley, D.W. and Smith, A.K. (1984). Microstructure of squid muscle and its influence on texture. Can. Inst. Food Sci. Technol., 17, 209213.

Suyama, M. (1980). Soshiki. In "Ika no Riyo," ed. by H. Satake. Koseisha Koseikaku, Tokyo, p.38 (in Japanese). 